\title{
1 In-vitro virucidal activity of hypothiocyanite and hypothiocyanite/lactoferrin mix against \\ 2 SARS-CoV-2
}

3

4 Luca Cegolon $^{1 *}$, Mattia Mirandola ${ }^{2}$, Claudio Salaris ${ }^{2}$, Maria Vittoria Salvati ${ }^{2}$, Cristiano Salata $^{2^{*}}$ and 5 Giuseppe Mastrangelo ${ }^{3}$

6

$7 \quad{ }^{1}$ Local Health Unit N.2 “Marca Trevigiana”, Public Health Department, Treviso, Italy

$8 \quad{ }^{2}$ Department of Molecular Medicine, Padua University, Padua, Italy

$9{ }^{3}$ Department of Cardiac, Thoracic, Vascular Sciences \& Public Health, Padua University, Padua, 10 Italy

*Correspondence to: 1.cegolon@gmail.com; cristiano.salata@unipd.it

14

Keywords: Hypothiocyanite, Lactoferrin, Lactoperoxidase system, ALX-009, SARS-CoV-2, COVID-19, virucidal activity, antiviral therapy

N. Words: 1933

N. Figure: 2

Supplementary figure: 1

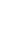

3

4

5

6

7


SARS-CoV-2 replicates efficiently in the upper airway during prodromal stage with resulting viral shedding into the environment from patients with active disease as well as from asymptomatic individuals. So far, virus spread has been exclusively contained by non-pharmacological interventions (social distancing, face masks, hand washing and several measures limiting business activities or movement of individuals) ${ }^{1,2}$. There is a need to find pharmacological interventions to mitigate the viral spread, supporting yet limiting the existing health protection measures while an effective and safe vaccine will hopefully become available. Hypothiocyanite and lactoferrin as part of the innate human immune system were shown to have a large spectrum of cidal activity against bacteria, fungi and viruses ${ }^{2,3}$. To test their virucidal activity against SARS-CoV-2 we conducted an in-vitro study. Here we show a dose-dependent virucidal activity of hypothiocyanite at micromolar concentrations, slightly improved by the presence of lactoferrin. The two substances are devoid of any cytotoxicity and may be administered combined by aerosol to exploit their antiviral activity at the port of entry (mouth, nasal cavity, conjunctiva) or exit (mouth, through emission of respiratory droplets) of SARS-CoV-2 in the human body. Furthermore, aerosol with hypothiocyanite and lactoferrin combined could also have a therapeutic effect in the lower respiratory tract, at the level of gas exchange units of the lung, preventing the devastating infection of alveolar type II cells where ACE2 is highly expressed. An in-vivo validation of in-vitro results is urgently required.

A critical problem with SARS-CoV-2 the etiological agent of COVID-19 is the high communicability of the infection, with a base reproductive number $\left(\mathrm{R}_{0}\right)$ estimated to fall within the range of 2-3, with a mean of 3.28, a median of 2.79 and an interquartile range of 1.16 , similar to SARS-CoV-1 $\left(\mathrm{R}_{0}=2-5\right)$, but much higher than MERS-CoV's $\left(\mathrm{R}_{0}=0.5\right)^{4-6} \cdot \mathrm{R}_{0}>1$ means selfsustaining spread of the disease unless infection prevention and control (IPC) measures are enforced to curb the viral transmission ${ }^{7}$. Differently from SARS-CoV-1, SARS-CoV-2 seems able to replicate efficiently in the upper airways epithelium also during the prodromal stage, when large amount of viruses can be shed into the environment from asymptomatic/pre-symptomatic individuals also during the incubation period, which can stretch up to 14 days ${ }^{1,2,8}$. Asymptomatic/pre-symptomatic individuals make up about $90 \%$ of patients infected by SARSCoV-2, thus rendering the spread of COVID-19 much easier than SARS, whose communicability was limited to the critical active phase of the disease, not during the incubation ${ }^{9}$.

So far, the spread of COVID-19 has been exclusively contained by non-pharmacological health protection measures, especially social distancing, use of face masks, hand washing, isolation of confirmed cases, quarantine for close contacts and a number of constraints on several business activities as well as on social freedom of individuals ${ }^{1,2}$. Since these public health measures dramatically impact on the economy of countries and the personal life of people, they cannot be imposed for long time.

Therefore, there is a need to find pharmacological interventions to prevent and control COVID-19, supporting yet mitigating the existing IPC measures while an effective and safe vaccine will hopefully become available. Natural products derived from the innate immune system could be exploited as candidates for broad-spectrum antimicrobial agents. In this regard, hypothiocyanite $\left(\mathrm{OSCN}^{-}\right)$and lactoferrin (LF) can represent promising candidates for new anti-infective therapies.

$\mathrm{OSCN}^{-}$is an anti-infectious agent, present in various exocrine secretions including the interface of the human central airways epithelium, that is produced by hydrogen peroxide $\left(\mathrm{H}_{2} \mathrm{O}_{2}\right)$ and 
thiocyanate (anion $\mathrm{SCN}^{-}$) in presence of a peroxidase enzyme (lactoperoxidase, LPO). While it is present in the human bronchi ${ }^{10}$, LPO is nearly absent in the alveoli ${ }^{11}$. On the other hand, the angiotensin-converting enzyme 2 (ACE2), the receptor used by SARS-CoV-2 to enter cells ${ }^{12}$, is widely expressed in airways, particularly in nasal epithelial cells and type II alveolar epithelial cells $^{13}$. The LPO-based system inactivates micro-organisms in the extracellular space, indeed the lack of $\mathrm{LPO} / \mathrm{H}_{2} \mathrm{O}_{2} / \mathrm{SCN}^{-}$in alveoli may result in devastating effects on ACE2-expressing alveolar type II cells ${ }^{14}$. In 2014, we have demonstrated for the first time that $\mathrm{OSCN}^{-}$reduces the influenza virus $\mathrm{A}(\mathrm{H} 1 \mathrm{~N} 1)$ pdm09 infectivity when the virus is challenged with $\mathrm{OSCN}^{-}$for $60 \mathrm{~min}$ at $37{ }^{\circ} \mathrm{C}$ before infection supporting the possibility to use it for influenza prevention and treatment ${ }^{15}$. Thereafter the antiviral activity of $\mathrm{OSCN}^{-}$was tested also against several other strains of influenza virus, confirming a strain independent virucidal effect ${ }^{16,17}$.

LF is a natural multifunctional protein belonging to the family of transferrins, which can be found in human milk and external secretions as saliva, tears, milk, nasal and bronchial secretions, gastrointestinal fluids and urine mucosal secretions ${ }^{18}$. As a part of the innate human immune system, LF was found to be 150 fold over-expressed in SARS patients as compared to healthy controls $^{19}$. LF has strong antiviral activity against a large range of DNA and RNA viruses ${ }^{20}$ and inhibits SARS-CoV-1 pseudovirus cell entry by binding the heparan sulfate proteoglycans of target cells ${ }^{21}$.

In view of the above considerations, we conducted an in-vitro study on $\mathrm{OSCN}^{-}$and a combination of $\mathrm{OSCN}^{-}$and $\mathrm{LF}$, with the aim of testing their cytotoxic effect and virucidal activity against SARS-CoV-2.

\section{Virucidal activity of $\mathrm{OSCN}^{-}$and $\mathrm{LF}$}

To investigate the virucidal activity of $\mathrm{OSCN}^{-}$against SARS-CoV-2 we used a recombinant Vesicular Stomatitis Virus (rVSV), encoding the reported gene luciferase instead of the viral glycoprotein, pseudotyped with the Spike (S) protein of SARS-CoV-2 (rVSV-S). It has been shown that VSV can be pseudotyped by the S protein obtaining a virus with a tropism dictated by the heterologous $\mathrm{S}$ envelope which represents an excellent surrogate of SARS-CoV-2 to study virus entry and viral neutralization ${ }^{22}$.rVSV, as single replication step virus, can be manipulated under biosafety level 2 conditions, thereby overcoming the biosafety concern due to the manipulation of highly pathogenic viruses ${ }^{23}$. To this end, rVSV-S was incubated with different $\mathrm{OSCN}^{-}$ concentrations for $60 \mathrm{~min}$ at $37^{\circ} \mathrm{C}$, then Vero cells were infected at multiplicity of infection (MOI) 0.065 focus forming unit (FFU) per cell. Sixteen hours post infection, cells were lysed and the luciferase expression was evaluated. As shown in Fig. 1a viral infection is inhibited in a dose dependent manner and the concentration capable of reducing the viral infectivity by $50 \%$ (IC50) was $4.64 \mu \mathrm{M}$, a value comparable with that we previously reported for influenza virus A(H1N1)pdm09 ${ }^{15}$. 
113

\section{4}

115

116

117

118

119

120

121

122

123

124

125

126

127

128

129

130

131

132

133

134

135

136

137

138

139 a

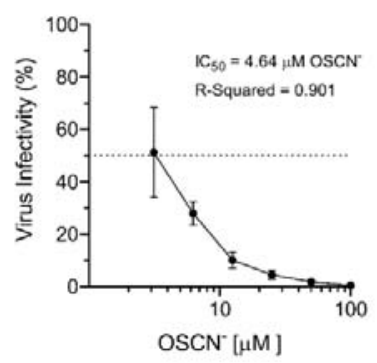

b

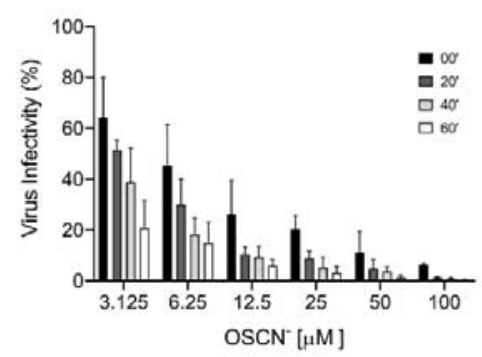

C

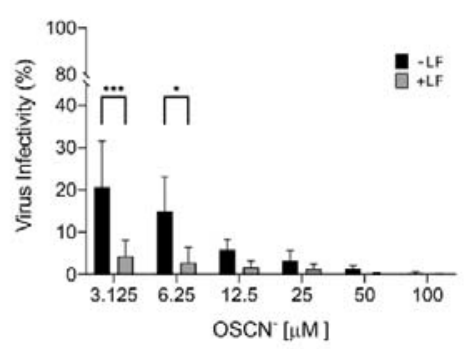

Figure 1. $\mathrm{OSCN}^{-}$and $\mathrm{OSCN}^{-} / \mathrm{LF}$ virucidal activity against the pseudovirus VSV-S. (a), Efficiency of pseudovirus infection after exposition at different $\mathrm{OSCN}^{-}$concentrations for $1 \mathrm{~h}$ at 37 ${ }^{\circ} \mathrm{C}$. (b), Evaluation of the virucidal activity of $\mathrm{OSCN}^{-}$after pseudovirus treatment for $0,20,40$, and 60 min at $37^{\circ} \mathrm{C}$ before the infection of target cells. (c), Comparison between $\mathrm{OSCN}^{-}$and $\mathrm{OSCN}^{-}+\mathrm{LF}$ virucidal activity after $1 \mathrm{~h}$ of pretreatment of VSV-S before cells infection. Data (mean $\pm \mathrm{SD}, \mathrm{N}=3$, experiments in duplicate) are percentages of no drug, set as $100 \%\left(^{*}=\mathrm{P}<0.05 ; * * *=\right.$ $\mathrm{P}<0.001)$.

To evaluate the correlation between the time of virus exposure to $\mathrm{OSCN}^{-}$and the virucidal activity, rVSV-S was incubated with $\mathrm{OSCN}^{-}$for 60,40 or 20 minutes before the infection of target cells (virus pre-treatment) or directly incubated (co-treatment) during the one hour of virus adhesion to cells ( 0 minutes, in Fig 1b). Although the efficiency of the virucidal activity was clearly time dependent in all the conditions tested, we observed a reduction of the viral infectivity of more than $50 \%$ until the concentration of $6.25 \mu \mathrm{M}$ (Fig 1b), when the virus was incubated with $\mathrm{OSCN}^{-}$before the infection. Moreover, starting from $\mathrm{OSCN}^{-}$concentration of $12.5 \mu \mathrm{M}$ a reduction of more than $50 \%$ was also observed for the virus treatment during the infection of cells.

We also investigated the virucidal activity of $\mathrm{OSCN}^{-}$and $\mathrm{LF}$ combination. Preliminary experiments with LF showed that concentrations of more than $1 \mathrm{~g} / \mathrm{L}$ are required to inhibit viral infection (data not shown). Then, we selected a concentration of $4 \mathrm{~g} / \mathrm{L}$ that was close to that previously used with $\mathrm{OSCN}^{-}$in experiments against bacteria ${ }^{24}$. The combination $\mathrm{OSCN}^{-} / \mathrm{LF}$ showed a significant increase of the virucidal activity at lower doses of $\mathrm{OSCN}^{-}$, with an inhibition of viral infection of more than $90 \%$ in comparison to a reduction of $80-85 \%$ observed with $\mathrm{OSCN}^{-}$(Fig. 1c) and $25 \%$ with LF alone (data not shown). These data suggest that, in our experimental conditions, $\mathrm{OSCN}^{-}$ has the main virucidal effect, while at lower $\mathrm{OSCN}^{-}$concentrations $\mathrm{LF}$ can contribute to improve the virus inactivation. Of note, addition of $\mathrm{OSCN}^{-}$and $\mathrm{LF}$ was not toxic to Vero cells, monitored for $24 \mathrm{~h}$ by the MTT test, indeed the inhibition of viral infectivity is due to the interference of the compounds on the capacity of the virus to infect cells (supplementary figure 1). 
140

141

142

143

144

145

146

147

148

149

150

151

152

153

154

155

156

157

158

159

160

161
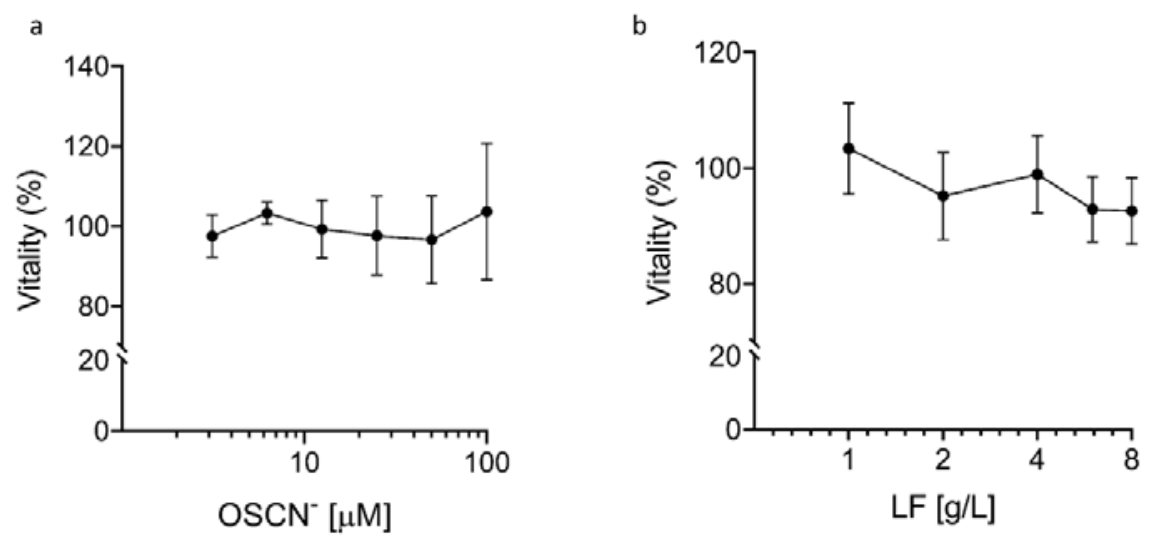

Supplemental Figure 1. Cytotoxicity of $\mathrm{OSCN}^{-}$and LF. The cytotoxicity of $\mathrm{OSCN}^{-}$(a) and LF (b) was evaluated on Vero cells after $24 \mathrm{~h}$ of treatment using the MTT assay. Data (mean $\pm \mathrm{SD}, \mathrm{N}=$ 3 , experiments in quadruplicate) are percentages of no drug, set as $100 \%$.

Finally, to validate the results obtained with the rVSV-S, we performed experiments with $\mathrm{OSCN}^{-}$ and $\mathrm{OSCN}^{-} / \mathrm{LF}$ using SARS-CoV-2. After virus-compound incubation for $60 \mathrm{~min}$, tenfold dilutions of virus-compound mix were inoculated on Vero-E6 cells (used for virus isolation and propagation) and the reduction of plaque generation was evaluated. Results reported in figure 2 confirmed the dose-dependent virucidal activity of $\mathrm{OSCN}^{-}$(fig 2a) and demonstrated that higher doses of $\mathrm{OSCN}^{-}$ can efficiently inhibit SARS-CoV-2 infection also with an incubation of $20 \mathrm{~min}$ (figure $2 \mathrm{~b}$ ). In contrast to the pseudovirus, the enhancement of the virucidal activity of $\mathrm{OSCN}^{-}$was less pronounced in presence of LF (figure 2c).

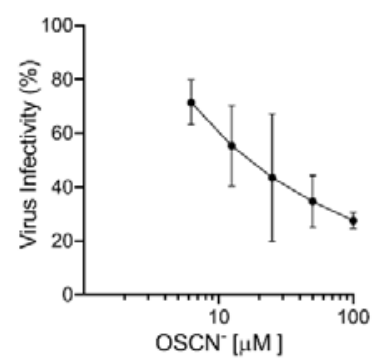

b

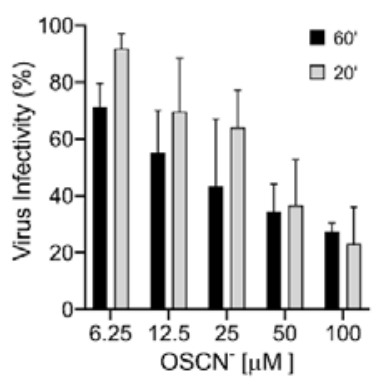

c

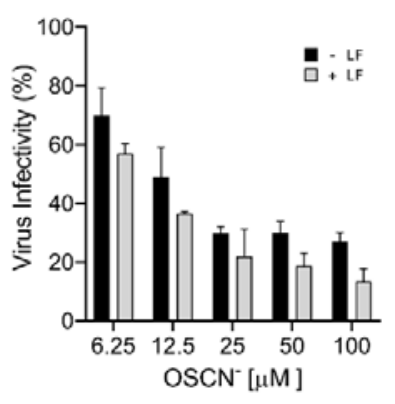

Figure 2. Virucidal activity of $\mathrm{OSCN}^{-}$and $\mathrm{OSCN}^{-} / \mathrm{LF}$ against SARS-CoV-2. SARS-CoV-2 was treated for $1 \mathrm{~h}$ at $37^{\circ} \mathrm{C}$ with $\mathrm{OSCN}^{-}$alone or supplemented with $\mathrm{LF}$ before infection of cells. The reduction of infectivity was evaluated by plaque assay. (a), virucidal effect of $\mathrm{OSCN}^{-}$. (b), Comparison between different times of virus- $\mathrm{OSCN}^{-}$exposition on the efficiency of the virucidal activity. (c), Evaluation of the combination $\mathrm{OSCN}^{-}+\mathrm{LF}$ on the virucidal activity. Data (mean $\pm \mathrm{SD}$, $\mathrm{N}=3$, experiments in duplicate) are percentages of no drug, set as $100 \%$. 
Overall, our results indicate that $\mathrm{OSCN}^{-}$has a strong virucidal activity against SARS-CoV-2, and the combination of $\mathrm{OSCN}^{-} / \mathrm{LF}$ further improved the $\mathrm{OSCN}^{-}$virucidal effect by moderate margin.

\section{Conclusions}

The pathogenesis of COVID-19 can be divided into three clinical stages depending on where the infection resides ${ }^{14}$. In the asymptomatic initial phase, COVID19 infection mostly resides in the nose where it elicits a minimal localized innate immune response. Scientists are looking for effective therapeutic strategies to reduce the viral shedding and disease spread. Very recently, a study evaluated the virucidal activity in-vitro of different commercially available oral rinses against SARS-CoV-2, assuming that oral rinsing might reduce the viral load of saliva and could thus lower the emission and transmission of SARS-CoV-2 through droplets. Viral infectivity of different SARS-CoV-2 strains was significantly reduced to undetectable levels by three formulations: Dequonal (active compounds: Dequalinium chloride and Benzalkonium chloride); Iso-Betadine mouthwash (Polyvidone-iodine) and Listerine Cool Mint (Ethanol and Essential oils) ${ }^{25}$. Thus, preliminary trials aimed to evaluate the reduction of viral shedding in confirmed COVID-19 patients have been registered ${ }^{26,27}$. In addition, it has been also shown that the mouth spray ColdZyme, used against common cold, inactivates SARS-CoV-2 in-vitro ${ }^{28}$. For the mild symptomatic phase, the infection is localized mostly in the pseudostratified epithelium of the larger airways and is accompanied by a more vigorous innate immune response. In the conducting airways, the epithelium can recover from the infection, because basal cells, progenitor for the bronchial epithelium, are spared. There may be more severe disease in the bronchioles, where club cells are likely infected. Mouthwashes and gargling are not effective treatments in this second phase, nor in the third (potentially lethal) phase of the disease, where the infection spreads into the gas exchange portion of the lung and infects ACE2-expressing alveolar type II cells. By contrast, given the absence of cytotoxic effect in our experimental conditions, $\mathrm{OSCN}^{-}$and $\mathrm{LF}^{-}$can enter the respiratory system in the form of aerosol and penetrate deep into the tracheobronchial tree up to alveolar sacs, inactivating both the viruses nearing the epithelium from outside and virions released from infected cells, thus mitigating or preventing all the three clinical stages of COVID-19 infection.

ALX-009, a combination of $\mathrm{OSCN}^{-}$and bovine LF developed by ALAXIA SAS for the treatment of respiratory cystic fibrosis pathogens, has already being successfully tested in a phase 1 clinical trial (RCT02598999) on healthy volunteers and patients affected by cystic fibrosis ${ }^{2}$. Interestingly, $\mathrm{OSCN}^{-}$and bovine LF concentrations in ALX-009 tested against pathogenic bacteria were considerably higher than those used in our experimental setting, reaching value of 3,600 $\mu \mathrm{M}$ and 8 $\mathrm{g} / \mathrm{L}$ respectively, which therefore should likely maximize their respective virucidal activity ${ }^{24}$. Considering the current emergency situation, ALX-009 could be rapidly tried in clinical settings to verify its in-vivo efficacy, with the view of preventing the eventual progression of the disease in symptomatic and pre-symptomatic individuals testing positive for COVID-19 at nasal-pharyngeal swabs, as well as to reduce the virus shedding in asymptomatic subjects. 


\section{References}

1. Cegolon L, Javanbakht M, Mastrangelo G. Nasal disinfection for the prevention and control of COVID-19: A scoping review on potential chemo-preventive agents. Int J Hyg Environ Health. 2020 Aug 18; 230: 113605.

2. Cegolon L. Investigating hypothiocyanite against SARS-CoV-2. Int J Hyg Environ Health. 2020; 227:113520.

3. Bruni N, Capucchio MT, Biasibetti E, Pessione E, Cirrincione S, Giraudo L, Corona A, Dosio F. Antimicrobial Activity of Lactoferrin-Related Peptides and Applications in Human and Veterinary Medicine. Molecules. 2016 Jun; 21(6): 752.

4. Liu Y, Gayle AG, Wilder-Smith A, Rocklöv J. The reproductive number of COVID-19 is higher compared to SARS coronavirus. J. Trav. Med. 2020; 1-4.

5. Poletto C, Pelat C, Lévy-Bruhl D, Yazdanpanah Y, Boëlle PY, Colizza V. Assessment of the Middle East respiratory syndrome coronavirus (MERS-CoV) epidemic in the Middle East and risk of international spread using a novel maximum likelihood analysis approach. EuroSurveill. 2014; 19 (6): pii=20699.

6. Kucharski AJ, Althaus CL, The role of superspreading in Middle East respiratory syndrome coronavirus (MERS-CoV) transmission. Euro Surveill. 2015; 20 (25), pii=21167.

7. Imai N , Cori A, Dorigatti I et al. Report 3: transmissibility of 2019-nCoV . 2020 . WHO Collaborating Centre for Infectious Disease Modelling, MRC Centre for Global Infectious Disease Analysis, J-IDEA, Imperial College London, UK.

8. Heymann, D. L., \& Shindo, N. (2020). COVID-19: what is next for public health?. The Lancet, 395(10224), 542-545.

9. Peiris, J. S., Yuen, K. Y., Osterhaus, A. D., \& Stöhr, K. (2003). The severe acute respiratory syndrome. New England Journal of Medicine, 349(25), 2431-2441.

10. Wijkstrom-Frei C, El-Chemaly S, Ali-Rachedi R, Gerson C, Cobas MA, Forteza R, Salathe M, Conner GE. Lactoperoxidase and human airway host defense. Am J Respir Cell Mol Biol. 2003 Aug;29(2):206-12. doi: 10.1165/rcmb.2002-0152OC. Epub 2003 Mar 6. PMID: 12626341.

11. Gerson, C., Sabater, J., Scuri, M., Torbati, A., Coffey, R., Abraham, J. W., ... \& Abraham, W. M. (2000). The lactoperoxidase system functions in bacterial clearance of airways. American Journal of Respiratory Cell and Molecular Biology, 22(6), 665-671.

12. Salata C, Calistri A, Parolin C, Palù G. Coronaviruses: a paradigm of new emerging zoonotic diseases. Pathog Dis. 2019 Dec; 77(9): ftaa006.

13. Yao Y, Wang H, Liu Z. Expression of ACE2 in airways: Implication for COVID-19 risk and disease management in patients with chronic inflammatory respiratory diseases. Clin Exp Allergy. 2020 Sep 25:10.1111/cea.13746. doi: 10.1111/cea.13746.

14. Mason RJ. Thoughts on the alveolar phase of COVID-19. Am J Physiol Lung Cell Mol Physiol. 2020 Jul 1;319(1):L115-L120. doi: 10.1152/ajplung.00126.2020.

15. Cegolon L, Salata C, Piccoli E, Juarez V, Palu' G, Mastrangelo G, Calistri A. In vitro antiviral activity of hypothiocyanite against $\mathrm{A} / \mathrm{H} 1 \mathrm{~N} 1 / 2009$ pandemic influenza virus. Int J Hyg Environ Health. 2014; 217(1): 17-22.

16. Patel, U., Gingerich, A., Widman, L., Sarr, D., Tripp, R. A., \& Rada, B. (2018). Susceptibility of influenza viruses to hypothiocyanite and hypoiodite produced by lactoperoxidase in a cellfree system. PloS one, 13(7), e0199167.

17. Gingerich, A., Pang, L., Hanson, J., Dlugolenski, D., Streich, R., Lafontaine, E. R., ... \& Rada, B. (2016). Hypothiocyanite produced by human and rat respiratory epithelial cells inactivates extracellular H1N2 influenza A virus. Inflammation research, 65(1), 71-80. 
18. Farnaud, S., \& Evans, R. W. (2003). Lactoferrin - a multifunctional protein with antimicrobial properties. Molecular immunology, 40(7), 395-405.

19. Reghunathan R, Jayapal M, Hsu L, Chng H, Tai D, et al. (2005) Expression profile of immune response genes in patients with Severe Acute Respiratory Syndrome. BMC Immunology 6: 2.

20. Berlutti F, Pantanella F, Natalizi T, Frioni A, Paesano R, Polimeni A, et al. Antiviral properties of lactoferrin-A Natural Immunity Molecule. Molecules. 2011;16:6992-7018.

21. Lang J, Yang N, Deng J, Liu K, Yang P, Zhang G, Jiang C. Inhibition of SARS pseudovirus cell entry by lactoferrin binding to heparan sulfate proteoglycans. PLoS One. 2011;6(8):e23710.

22. Nie J, Li Q, Wu J, Zhao C, Hao H, Liu H, Zhang L, Nie L, Qin H, Wang M, Lu Q, Li X, Sun Q, Liu J, Fan C, Huang W, Xu M, Wang Y. Quantification of SARS-CoV-2 neutralizing antibody by a pseudotyped virus-based assay. Nat. Protoc. (2020). Sep 25. doi: 10.1038/s41596-020-0394-5.

23. Salata C, Calistri A, Alvisi G, Celestino M, Parolin C, Palù G. Ebola Virus Entry: From Molecular Characterization to Drug Discovery. Viruses. 2019 Mar 19;11(3):274.

24. Tunney MM, Payne JE, McGrath JS, Einarsson GG, Ingram RJ , Gilpin DF, Juarez-Perez V, Elborn JS. Activity of hypothiocyanite and lactoferrin (ALX-009) against respiratory cystic fibrosis pathogens in sputum. J Microb Chemother. 2018 Dec 1;73(12):3391-3397.

25. Meister TL, Brüggemann Y, Todt D, Conzelmann C, Müller JA, Groß R, Münch J, Krawczyk A, Steinmann J, Steinmann J, Pfaender S, Steinmann E. Virucidal Efficacy of Different Oral Rinses Against Severe Acute Respiratory Syndrome Coronavirus 2. J Infect Dis. 2020 Sep 14;222(8):1289-1292.

26. Gansky SA, Banava S. Antiseptic Mouthwash / Pre-Procedural Rinse on SARS-CoV-2 Load (COVID-19) (AMPoL). https://clinicaltrials.ucsf. edu/trial/NCT04409873. (accessed November 8, 2020).

27. Kazim SMR, A Clinical Trial of Gargling Agents in Reducing Intraoral Viral Load Among COVID-19 Patients (GARGLES). https://clinicaltrials. gov/ct2/show/NCT04341688. (accessed November 8, 2020).

28. Gudmundsdottir Á, Scheving R, Lindberg F, Stefansson B. Inactivation of SARS-CoV-2 and $\mathrm{HCoV}-229 \mathrm{E}$ in vitro by ColdZyme a medical device mouth spray against the common cold. $\mathrm{J}$ Med Virol. 2020 Sep 25:10.1002/jmv.26554.

\section{Methods}

$\underline{\text { Cell culture and viruses }}$

Vero (African green monkey kidney cells, ATCC® CCL-81), Vero E6 (ATCC® CRL1586) and HEK293T (ATCC® CRL-11268TM) cells were grown in Dulbecco's modified Eagle's medium (D-MEM) containing 10\% heat-inactivated fetal bovine serum (FBSi). Cells were maintained in a $5 \% \mathrm{CO}_{2}$ incubator at $37 \square{ }^{\circ} \mathrm{C}$, routinely checked for mycoplasma and confirmed negative. Culture medium and FBSi were obtained from Gibco (Thermofisher).

SARS-CoV-2 (Genbank: MW000351) and the rVSV $\Delta$ G-Luc, a recombinant Vesicular Stomatitis Virus containing the gene encoding for the luciferase protein in place of the VSV-G gene ${ }^{29}$, were used in the experiments.

$\underline{\text { Virus stock preparation and titration }}$

Vero E6 cells were seeded in T175 flasks and then infected with SARS-CoV-2 (MOI of $\approx 0.1$ ). At $72-96 \mathrm{~h}$ post infection (p.i.), supernatants were collected, centrifuged at 2,300 rpm for $10 \mathrm{~min}$, then 
stored in aliquots at $-80{ }^{\circ} \mathrm{C}$. Viral titer was determined by plaque assay on Vero E6 cells seeded on 24-well plates. Tenfold virus dilutions were prepared in DMEM and inoculated on confluent VeroE6 cells for $1 \mathrm{~h}$ at $37^{\circ} \mathrm{C}$. After that, virus inoculum was removed from each well and cells were overlaid with $300 \mu \mathrm{L}$ of $0.6 \%$ carboxymethylcellulose (Merck) diluted in DMEM supplemented with $2 \%$ FBSi. Seventy-two h p.i., cells were fixed adding $300 \mu \mathrm{L}$ of $5 \%$ formaldehyde (Merck) in PBS $1 x$ for $30 \mathrm{~min}$ at room temperature. Then, cells were stained with crystal violet in $20 \%$ ethanol. Virus titer was measured as plaque-forming units per milliliter (PFU/mL) based to the plaques formed in cell culture upon infection. All studies with viable SARS-CoV-2 were performed in the certified BSL3 laboratory of the Department of Molecular Medicine, University of Padova, in biological safety cabinets.

For SARS-CoV-2-pseudotyped VSV production (rVSV-S), HEK293T cells were seeded in T175 flasks and then transfected by calcium phosphate-DNA preciptation with $40 \mu \mathrm{g}$ of pSARS-CoV-2spike plasmid. After $24 \mathrm{~h}$, cells were infected with the rVSV $\Delta \mathrm{G}-L u c$ virus at the multiplicity of infection (MOI) of 4 fluorescent focus-forming units (FFU)/cell. Sixteen hours p.i., cell culture supernatants were harvested and cell debris were cleared by centrifugation (2,300 rpm for 7 minutes at $4{ }^{\circ} \mathrm{C}$ ). Then, virus particles were pelleted by ultracentrifugation on a $20 \% \mathrm{p} / \mathrm{v}$ a sucrose cushion $\left(27,000 \mathrm{rpm}\right.$ for $150 \mathrm{~min}$ at $\left.4{ }^{\circ} \mathrm{C}\right)$ in a Beckmann SW 28 Ti Swinging-Bucket rotor. Pellets were resuspended in $1 \mathrm{~mL}$ of ice-cold $\mathrm{PBS} 1 \mathrm{X} /$ tube and mixed. Subsequently, the virus was aliquoted and stored at $-80{ }^{\circ} \mathrm{C}$ until use.

Titration of virus was determined by immunofluorescence on Vero cells seeded on 96-well plates. Viral stock was tenfold serially diluted in DMEM and inoculated on confluent Vero cells for $1 \mathrm{~h}$ at $37^{\circ} \mathrm{C}$. Then, cells were washed and DMEM supplemented with $10 \% \mathrm{FBSi}$ was added. After $18 \mathrm{~h}$, cells were fixed with precooled methanol-acetone for $1 \mathrm{~h}$ at $-20^{\circ} \mathrm{C}$. Immune staining was performed by incubation with 1:3000 anti-VSV-M [23H12] monoclonal antibody (Kerafast) on the infected cells for 90 minutes at $37^{\circ} \mathrm{C}$, followed by incubation with 1:1000 anti-rabbit Alexa Fluor ${ }^{\circledR}$ 488 (Thermo Fisher Scientific) for 60 minutes at $37^{\circ} \mathrm{C}$. The fluorescent foci in each well were counted and viral titer was expressed as focus-forming units per $\mathrm{mL}(\mathrm{FFU} / \mathrm{mL})^{30}$.

\section{$\underline{\text { Compounds preparation and cytotoxicity assay }}$}

$\mathrm{OSCN}^{-}$solution was prepared via enzymatic reaction with an automated equipment EOLEASE® (Alaxia, Lyon, France). Due to its intrinsic reactivity, each solution freshly prepared was used alone or combined with Lactoferrin within 15 min after preparation. Reagents for the $\mathrm{OSCN}^{-}$production were provided by Alaxia.

Pharma-grade lyophilized Lactoferrin (purity >98\%) was made available by Alaxia, as sterile vials. Lyophilized Lactoferrin was reconstituted as solution with $0.9 \%$ sodium chloride solution at 10 $\mathrm{g} / \mathrm{L}$.

Compound dilutions for virus treatment were performed in Minimum Essential Media (MEM) purchased by Gibco.

Cytotoxicity of $\mathrm{OSCN}^{-}$and LF was determined on Vero and Vero-E6 cells after $24 \mathrm{~h}$ of treatment. Cell viability was tested with an assay based on the reduction of a tetrazolium salt (MTT Cell Proliferation Assay, Thermofisher) in a 96-well plate format according to the manufacturer's instructions.

Virucidal assay 
To evaluate the $\mathrm{OSCN}^{-}$and LF virucidal activity, 4 × $10^{4} \mathrm{FFU}$ of rVSV-S were incubated for $1 \mathrm{~h}$ at $37{ }^{\circ} \mathrm{C}$ with $0-3.125-6.25-12.5-25-50$ and $100 \mu \mathrm{M}$ of $\mathrm{OSCN}^{-}$with or without $4 \mathrm{~g} / \mathrm{L}$ of LF. Positive control (mock sample) was treated with the solution used to prepare the $\mathrm{OSCN}^{-}$simulating the max $\mathrm{OSCN}^{-}$concentration. Next, Vero cells seeded on 96-well plates were infected for $1 \mathrm{~h}$ at $37^{\circ} \mathrm{C}$. Eighteen hours later, infection was evaluate measuring the relative light unit (RLU) with a VICTOR Multilabel Plate Reader (PerkinElmer) using the Steady-Glo® Luciferase Assay System (Promega).

In the case of SARS-CoV-2, 1 x $10^{5} \mathrm{PFU}$ were incubated for $1 \mathrm{~h}$ at $37{ }^{\circ} \mathrm{C}$ with $0-6.25-12.5-25$ - 50 and $100 \mu \mathrm{M}$ of $\mathrm{OSCN}^{-}$with or without $4 \mathrm{~g} / \mathrm{L}$ of LF. Next, tenfold virus dilutions were prepared in MEM and processed as above reported for the plaque assay. Viral titer was calculated for each sample and the virucidal activity was measured evaluating the efficiency of the infection in comparison to the mock treated control.

\section{$\underline{\text { Statistical analysis }}$}

All the experiments were performed in duplicate in at least three independent biological replicates. Statistical analysis was carried out with GraphPad Prism the one-way ANOVA test. The threshold for statistical significance was $\mathrm{P}<0.05$. All details on sample size and $\mathrm{P}$ values for each experiment are provided in the relevant figure or its legend. Curve fitting was performed to determine IC50 values using a sigmoidal 4PL model in GraphPad Prism 8 software.

\section{Methods References}

29. Whitt, M.A. Generation of VSV pseudotypes using recombinant $\Delta \mathrm{G}-\mathrm{VSV}$ for studies on virus entry, identification of entry inhibitors, and immune responses to vaccines. J. Virol. Methods. 169, 365-374 (2010).

30. Salata, C. et al. Amiodarone and metabolite MDEA inhibit Ebola virus infection by interfering with the viral entry process. Pathog. Dis. 73, ftv032 (2015).

\section{Acknowledgements}

We are grateful to Alaxia SAS that provided protocols, equipment and reagents to prepare $\mathrm{OSCN}^{-}$ and LF. We thank Michael Whitt, University of Tennessee, Memphis, USA, for providing the VSV $\Delta$ G-Luc and Maria Rita Gismondo, L. Sacco University Hospital, Milan, Italy, for providing the SARS-CoV-2.

\section{Authors Contributions}

L.C. and Cr.S. conceived the project and wrote the draft. Cr.S. propagate the SARS-CoV-2, performed experiments with SARS-CoV-2, provided reagents, and coordinated the project. Cl.S. performed experiments with SARS-CoV-2 and cell culture, collected and analyzed the data. M.M and M.V.S. performed experiments with rVSV-S and cell culture, collected and analyzed the data. G.M. contributed to the initial conceptualization of the project, and helped with data interpretation.

\section{Competing interests}


377 Authors did not accept honoraria or other payments from Alaxia or other pharmaceutical industries.

378 No other conflicts of interest have to be declared.

379

380 Data availability statement

381 Raw data are available upon request.

382 Additional information

383 Supplementary information is available for this paper

384 Correspondence and requests for materials should be addressed to L.C. or Cr.S.

385

386

387

388

389

390 